\title{
Vulvar Eccrine Adenocarcinoma
}

National Cancer Institute

\section{Source}

National Cancer Institute. Vulvar Eccrine Adenocarcinoma. NCI Thesaurus. Code C40305.

An eccrine adenocarcinoma that arises from the sweat glands in the vulva. 